\title{
Developing a new national MDMA policy: Results of a multi- decision multi-criterion decision analysis (MD-MCDA)
}

Jan van Amsterdam, Gjalt-Jorn Ygram Peters, Ed Pennings, Tom Blickman, Kaj Hollemans, Joost J. Breeksema, Johannes Ramaekers, Cees Maris, Floor van Bakkum, Ton Nabben, Willem Scholten, Tjibbe Reitsma, Judith Noijen, Raoul Koning, Wim van den Brink

This preprint contains the full text of the article "Developing a new national MDMA policy: Results of a multi-decision multi-criterion decision analysis (MD-MCDA)" that has been submitted to the Journal of Psychopharmacology. This preprint has DOI 10.31219/osf.io/txy5z and is hosted at https://osf.io/txy5z.

Note that this is not the final text of the manuscript. The final published version will likely deviate from this version, so before citing this manuscript, check back at https://osf.io/txy5z and consult the published version, or an updated version of this preprint, if available.

The code and produced figures for this manuscript are available at the Open Science Framework at https://osf.io/h58r6/ and at the corresponding GitLab repository at https://gitlab.com/denktank/mdma-policy-mdmcda. Note that this repository has been frozen in the state it was in when the revision of this article was submitted: that public registration is available at https://osf.io/pw4gh and contains all analyses and results.

There is an online app where you can define your own scenario (policy model) and specify your own weights for the criteria. This app is available through https://mdmapolicy.com/app.

This project uses the mdmcda $R$ package, which is available from GitLab at https://rpackages.gitlab.io/mdmcda.
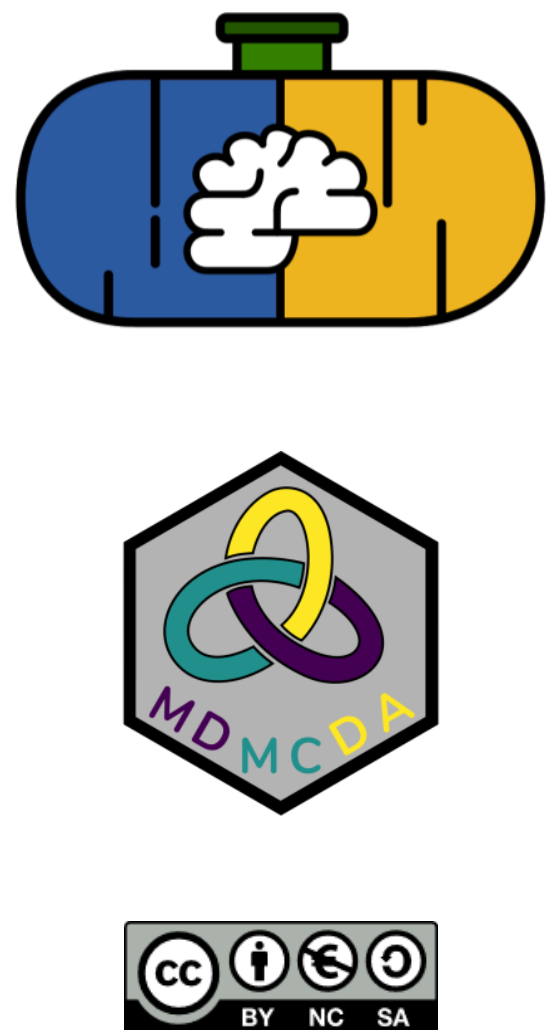


\section{Developing a new national MDMA policy:}

\section{Results of a multi-decision multi-criterion decision analysis (MD-MCDA)}

Jan van Amsterdam*1, Gjalt-Jorn Ygram Peters* 2, Joost Breeksema ${ }^{3}$, Ed Pennings 4 , Tom Blickman ${ }^{5}$, Kaj Hollemans ${ }^{6}$, Johannes G. Ramaekers ${ }^{7}$, Cees Maris ${ }^{8}$, Floor van Bakkum* 9 , Ton Nabben* ${ }^{10}$, Willem Scholten ${ }^{11}$, Tjibbe Reitsma ${ }^{12}$, Judith Noijen ${ }^{*}$, Raoul Koning ${ }^{9}$ and

Wim van den Brink ${ }^{1}$

1 Department of Psychiatry, Amsterdam University Medical Center, University of Amsterdam, P.O. Box 22660, 1100 DD Amsterdam, The Netherlands

2 Faculty of Psychology, Open University of the Netherlands, P.O. Box 2960, 6401 DL Heerlen, The Netherlands

3 Department of Psychiatry, Leiden University Medical Center, Albinusdreef 2, 2333 ZA Leiden, The Netherlands; University Centre of Psychiatry, University Medical Centre Groningen, Hanzeplein 1, 9713 GZ Groningen, The Netherlands

4 The Maastricht Forensic Institute, Maastricht, Oxfordlaan 70, 6229 EV Maastricht, The Netherlands

5 Transnational Institute (TNI), De Wittenstraat 25, 1052 AK Amsterdam, The Netherlands

6 KH Legal Advice, Van Diemenstraat 202/1.7, 2518 VH Den Haag, The Netherlands

7 Department of Neuropsychology and Psychopharmacology, Faculty of Neuroscience and Psychology, Maastricht University, P.O. Box 616, 6200 MD Maastricht, The Netherlands

8 Faculty of Law, University of Amsterdam, P.O. Box 15654, 1001 ND Amsterdam, The Netherlands

9 Jellinek, Prevention, Jacob Obrechtstraat 92, 1071 KR Amsterdam, The Netherlands

10 Department of Urban Management, Faculty Society and Law, Amsterdam University of Applied Sciences, Wibautstraat 3b, 1091 GH Amsterdam, The Netherlands

11 Willem Scholten Consultancy, Wielsekade 64, 3411 AD Lopik, The Netherlands

12 Stichting Drugsbeleid, Groot Heiligland 67, 2011 EP Haarlem, The Netherlands

\footnotetext{
* member of the steering group
} 


\begin{abstract}
Background: MDMA (ecstasy, 3,4-methylenedioxymethamphetamine) has a relatively low harm and low dependence liability but is scheduled on List I of the Dutch Opium Act together ("hard drugs"). Concerns surrounding increasing MDMA-related criminality coupled with the possibly inappropriate scheduling of MDMA initiated a debate to revise the current Dutch ecstasy policy.

Methods: An interdisciplinary group of eighteen experts on health, social harms, and drug criminality and law enforcement reformulated science-based the Dutch MDMA policy using multi-decision multi-criterion decision analysis (MD-MCDA). The experts collectively formulated policy instruments and rated their effects on 25 outcome criteria, including health, criminality, law enforcement and financial issues, thematically grouped in six clusters.
\end{abstract}

Results: The experts scored the effect of 22 policy instruments, each with 2-7 different mutually exclusive options, on 25 outcome criteria. The optimal policy model was defined by the set of 22 policy instrument options which gave the highest overall score on the 25 outcome criteria. Implementation of the optimal policy model, including regulated MDMA sales, decreases health harms, MDMA-related organised crime, and environmental damage, as well as, increases state revenues, and quality of MDMA products and user information. This model was slightly modified to increase its political feasibility. Sensitivity analyses showed that the outcomes of the current MD-MCDA are robust and independent of variability in weight values.

Conclusion: Present results provide a feasible and realistic set of policy instrument options to revise the legislation toward a rational MDMA policy that is likely to reduce both adverse (public) health risks and MDMA-related criminal burden.

Key words: ecstasy, XTC, MDMA, risk assessment, MCDA, adverse effects, criminality 


\section{Introduction}

Ecstasy (MDMA, 3,4-methylenedioxymethamphetamine) is a widely used drug, mainly by urban, higher educated, young adults at dance events and house parties (Nabben 2010). Typically, ecstasy is used only a few times a year (Nabben et al. 2018; Szigeti et al. 2018; van Laar and van Ooyen-Houben 2017). In the Netherlands, MDMA was placed on List I of the Dutch Opium Act (hard drugs, Schedule A in the UK) in 1988, i.e. three years after the WHO Expert Committee on Drug Dependence had recommended that MDMA should be included in Schedule I of the 1971 Convention on Psychotropic Substances. The basis for this decision was unclear, and still is. The WHO technical report stated that at that time there was no data "available concerning its clinical abuse liability, nature and magnitude of associated public health or social problems, or epidemiology of its use and abuse" (WHO 1985). Therefore, it remains unclear why MDMA was classified as a substance "whose liability to abuse constitutes an especially serious risk to public health" (WHO 2003). One argument for "scheduling" MDMA in Schedule I was that there was insufficient evidence for any therapeutic benefit. In the Netherlands, MDMA was scheduled on List I of the Opium Act because of concerns about large-scale trade and production of ecstasy, i.e., not because of emerging health concerns. Despite this listing, last-year prevalence of ecstasy use has steadily increased ever since, but stabilized in recent years at around three percent of the adult population (van Laar et al. 2019). Another issue is that MDMA has meanwhile been recognized as a promising pharmacological add-on to the psychotherapy of patients with PTSD. Such benefits, as well as the adverse effects and health risks of MDMA were recently reviewed (van Amsterdam et al. 2020a; van Amsterdam et al. 2020b).

The dependence liability of MDMA is low and its use is generally less harmful than other List I drugs, e.g. amphetamine, cocaine and heroin (Nutt et al. 2010; van Amsterdam et al. 2010). One may therefore question whether the current scheduling of MDMA is justified. Despite being a List I substance, MDMA is illegally produced in the Netherlands in large quantities and further distributed world-wide. The illegal MDMA-production in the Netherlands is accompanied by steady increase in serious crime, including the dumping of chemical waste by clandestine drug laboratories, money laundering, threats to civil servants and the penetration of criminal interests in the "upper world" in the last two decades (Tops and Tromp 2019; Tops et al. 2018). Faced with increasing public awareness of a possibly inappropriate 
scheduling of MDMA and the growing concerns about MDMA-related crime, many Dutch policy makers and influencers are currently considering a revision of the national MDMA policy.

To provide a rational basis for this challenging task, a multi-disciplinary group of eighteen experts was invited to participate in decision meetings to develop a science based and politically feasible MDMA policy (Hall and Lynskey 2009). Using the multi-decision multicriteria decision analysis (MD-MCDA) approach, a more extensive variant of MCDA (Nutt et al. 2010; Rogeberg et al. 2018), the experts formulated 95 policy instrument options and scored their effects on 25 outcome criteria. Final aim of the experts was to identify the optimal MDMA policy model, i.e. a policy model with the highest gain and the lowest damage in terms of public health, criminality, financial burden, and other factors. In MD-MCDA, weighting factors are assigned to the outcome criteria which allows subsequent summation of effects on a set of unrelated outcomes (e.g. health harms plus crime related costs). The MCDA approach was previously successfully applied to rank four policy models for alcohol and cannabis (Rogeberg et al. 2018) and the relative harm of some twenty drugs (van Amsterdam et al. 2015a; van Amsterdam et al. 2015b).

In the current report, we describe the MD-MCDA facilitated definition of the rational and optimal MDMA policy model which was slightly fine-tuned to increase the political feasibility. Present results may guide the development of feasible and realistic instruments to revise the legislation of a rational MDMA policy that considers both adverse (public) health risks and MDMA-related criminal burden.

\section{Methods}

MD-MCDA assessment procedure

A consensus procedure using MD-MCDA was applied with different iterations, considering previously obtained information to reach the next rating, i.e. with each iteration, this information is passed on to the next iteration. The different steps in this process are outlined below (see also Fig. 1). 
STEP 1

Selection of experts

STEP 3

Definition of models
STEP $2 b$

Definition of

policy options
STEP 4

Scoring the policy options
STEP 2a
Definition
outcome criteria

STEP 5

Estimation of weights
STEP 6

Calculation of final scores

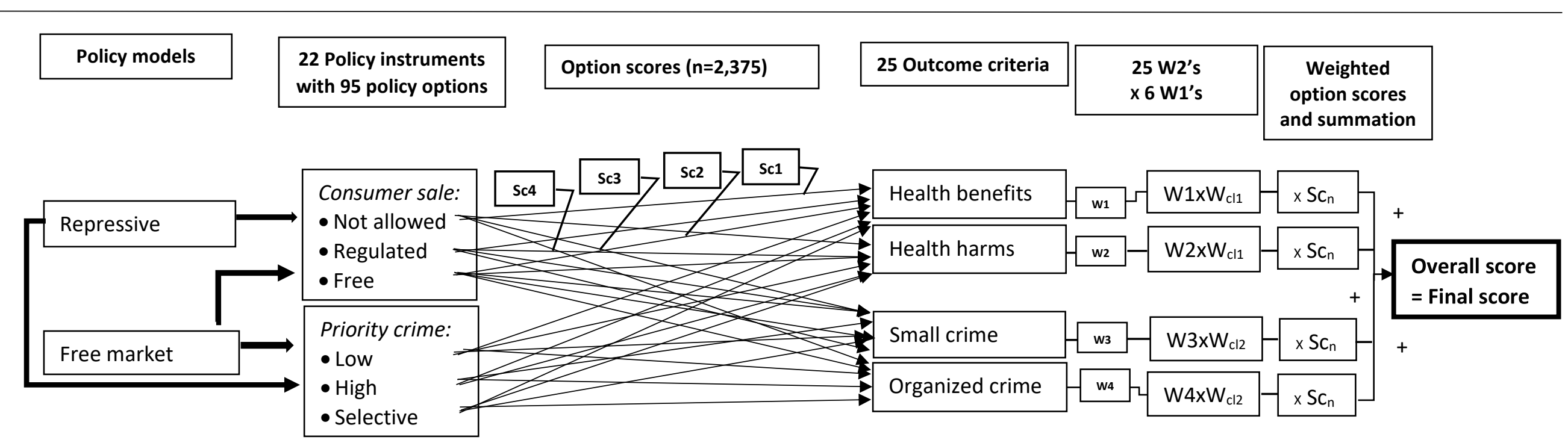

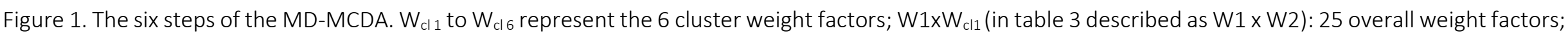
$S c_{n}$ to $S_{n+1}$ are the scores for the policy options obtained in step 4; multiplication of the overall weight factor of the criterion with $S c_{n}$ gives the weighted option score. Summation of 22 weighted selected policy options gives the overall score (final score) of a constructed model. 
Table 1. Description of the 95 policy instrument options sorted per policy instrument $(n=22)$. The 22 options with the description not applicable (always scored as zero) are not included listed.

\begin{tabular}{|c|c|c|c|}
\hline \multicolumn{2}{|c|}{ Policy instruments } & \multicolumn{2}{|c|}{ Policy instrument options } \\
\hline Nr. & Name & $\mathrm{N}$ & Description \\
\hline 1 & Possession & 4 & $\begin{array}{l}\text { Possession is illegal; user quantity is condoned; user quantity is } \\
\text { legal, higher quantities condoned; possession is legal }\end{array}$ \\
\hline 2 & Packaging & 4 & $\begin{array}{l}\text { Plain packaging with prevention message; only plain packaging; } \\
\text { only prevention message; no restrictions }\end{array}$ \\
\hline 3 & Advertising & 5 & $\begin{array}{l}\text { Advertising not allowed; packaging advertising only; age limited } \\
\text { advertising only; business to business advertising only; advertising } \\
\text { allowed }\end{array}$ \\
\hline 4 & Sales across companies & 5 & $\begin{array}{l}\text { Illegal; regulated; analogous to commodity law; analogous to } \\
\text { pharmaceutical law; allowed }\end{array}$ \\
\hline 5 & Sales to consumers & 5 & $\begin{array}{l}\text { Not allowed; regulated; analogous to commodity law; analogous to } \\
\text { pharmaceutical law; allowed }\end{array}$ \\
\hline 6 & Age limit & 3 & No age limit; age limit is 18 years; age limit is higher than 18 years \\
\hline 7 & Punishable & 3 & Nobody punishable; seller punishable; seller and buyer punishable \\
\hline 8 & $\begin{array}{l}\text { Legal requirements for } \\
\text { selling }\end{array}$ & 2 & No license required; license required \\
\hline 9 & $\begin{array}{l}\text { Price restrictions for } \\
\text { consumer sale }\end{array}$ & 2 & No price restricions; minimum pricing \\
\hline 10 & $\begin{array}{l}\text { MDMA quality rules } \\
\text { (QA) }\end{array}$ & 2 & $\begin{array}{l}\text { No quality definition/requirements; quality definition/requirements } \\
\text { in place }\end{array}$ \\
\hline 11 & Sanctioning QA rules & 3 & None; mild; severe \\
\hline 12 & Monitoring & 3 & None; selective; extensive \\
\hline 13 & $\begin{array}{l}\text { Health promotion (HP) } \\
\text { funding }\end{array}$ & 3 & No funding; minimal funding; substantial funding \\
\hline 14 & $\begin{array}{l}\text { Control prevention } \\
\text { policy }\end{array}$ & 3 & None; weak; strong \\
\hline 15 & $\begin{array}{l}\text { Health promotion } \\
\text { perspective }\end{array}$ & 2 & Abstinence; harm reduction \\
\hline 16 & $\begin{array}{l}\text { Government } \\
\text { responsible for HP }\end{array}$ & 4 & $\begin{array}{l}\text { No government; regional government; national government; both } \\
\text { governments }\end{array}$ \\
\hline 17 & Production of MDMA & 5 & $\begin{array}{l}\text { Illegal; regulated; analogous to commodity law; analogous to } \\
\text { pharmaceutical law; allowed }\end{array}$ \\
\hline 18 & Export status & 2 & Export is illegal; export is legal \\
\hline 19 & International strategy & 6 & $\begin{array}{l}\text { Compliant; violation; based on condoning; inter se; exceptional } \\
\text { position; adjustment of treaties }\end{array}$ \\
\hline 20 & Priority crime fighting & 3 & Low; selective; high \\
\hline 21 & Maximum penalty & 2 & Retain present sanction; more severe sanction \\
\hline 22 & Confiscation & 2 & Unchanged; intensify \\
\hline \multicolumn{2}{|c|}{ SUM 1-22 } & 73 & \\
\hline
\end{tabular}




\section{Step 1. Selection of experts}

The steering group (JvA, GJP, FB, TN, JN) invited 18 experts to participate in the expert panel. The prerequisite for selection was that every expert had a specific expertise and was independent or acted independently i.e. not bound by or accountable to political parties or ministries involved in either drug policy or drug enforcement. The expertise represented in the expert panel $(n=18)$ included the following domains: pharmacology, toxicology, pharmacy, philosophy, ethics, anthropology, drug enforcement, epidemiology, neurobiology, medicine, philosophy of law, criminology, law, national and international drug policy, drug prevention and behavioural sciences.

\section{Step 2. Definition of policy instruments and outcomes}

Every drug policy consists of a set of policy instruments with an impact on pre-defined outcomes. In step 2a, the experts selected 25 outcome criteria (e.g. prevalence of use, health and social harms, criminal burden, crime costs, stigmatization), grouped in the following six clusters: (A) 'Use'; (B) 'User Health'; (C) 'Crime'; (D) 'Financial'; (E) 'International'; and (F) 'Environment' (cf. Table 1, upper panel). A seventh outcome cluster (cluster G: 'Consistent with either conservative or liberal values') was included, but the scores were excluded from the analysis, because of their high level of subjectivity. In step $2 b$, the expert group formulated 22 policy instruments, each having 2-7 options, thus resulting in 95 policy instrument options (cf. Table 1).

\section{Step 3. Definition of five policy models}

A policy model is defined as a set of distinct choices for each of the 22 policy instruments, and the purpose of the MD-MCDA process is to identify the policy model that achieves the highest overall weighted score on the policy outcomes: the optimal model. To compare this optimal model to other commonly referenced policy proposals, we also specified four drug policy models by identifying how these would be defined in terms of our 22 policy instruments. These comparison models were: (1) the "coffeeshop model", (2) the "adapted coffeeshop model", (3) the "free market" model, and (4) the "repressive" model. Model 1 and 2 reflect two drug models described in the current Dutch legislation: the "coffeeshop model" and the "adapted coffeeshop model" with legal production and delivery of cannabis to the coffeeshop (Commission Knottnerus 2018; Dutch Government 2019c). Similarly, the "free market" and the "repressive" model (model 3 and 4) with their typical characteristics were constructed by 
assembling the applicable policy options. Finally, a fifth model ("X-shop model") is constructed (see below).

After the scoring of all policy options and the weight factors (see below), the optimal policy model was automatically generated by combining the 22 highest rated options per policy instrument. In a similar way, the worst policy model was assembled by combining the 22 lowest rated options. In some cases, 2-3 instrument options with the same score were applicable. The optimal model was then tweaked to a so-called "X-shop model" (model 5) to increase the political feasibility of the optimal model, and because it contained some mutually incompatible options. The X-shop model was constructed by selecting the applicable set of instrument options which legally impose regulated distribution and sales of ecstasy. The overall score of the five policy models was compared with that of the optimal and worst policy model.

Step 4. Scoring the effects of policy instrument options

Based on their own expertise, the selected experts rated the effect of the policy instrument options on the outcome criteria. In addition, experts shared their expert information with the other members of the panel and they were provided by an extensive 'state-of-the-art' document, covering the published and grey literature about the 25 outcomes related to ecstasy (van Amsterdam et al. 2020a; van Amsterdam et al. 2020b).

Each of the 22 policy instruments has several (2-7) possible options resulting in 95 policy instrument options, each of which may have a different impact on each of the 25 policy outcomes. Prior to scoring the 95 policy instrument options, consensus anchor values were set by the experts for each of the 25 outcomes, which represent the estimated maximal negative and maximal positive impact (effect) that a specific policy instrument can have on the outcome. As a rule, the anchors were set at zero for the current legal situation (i.e. MDMA on List I of the Dutch Opium Law), at -100 for a maximal negative impact and at +100 for a maximal positive impact compared to the current situation. However, for 12 of the 25 outcomes, the status quo more closely approximated the worst or best possible situation. In such cases, the anchors were adjusted to reflect this (cf. Table 2; e.g. there are currently no economic boycotts so that the situation can only deteriorate leading to a maximum anchor value of zero).

Guided by a moderator (who did not participate in the scoring), the experts rated the (relative) impact of each of the 95 policy instrument option on all 25 outcomes yielding 2,375 (95 x 25) 
Table 2. Pre-set anchor values of outcome criteria if different from -100 or +100 (12 of 25 outcomes).

\begin{tabular}{|clcc|}
\hline Nr. & Outcome & $\begin{array}{c}\text { Maximal } \\
\text { Negative effect }\end{array}$ & $\begin{array}{c}\text { Maximal } \\
\text { Positive effect }\end{array}$ \\
\hline 1 & Use frequency and intensity by users & -100 & 50 \\
2 & Use in vulnerable populations & -50 & 100 \\
10 & Shift to other drugs & -100 & 25 \\
12 & Criminalisation of users & -100 & 50 \\
13 & MDMA-related small crime & -100 & 50 \\
16 & International trafficking of MDMA & -10 & 100 \\
17 & State revenue (other) & 0 & 100 \\
18 & State revenue (VAT) & 0 & 100 \\
20 & Costs related to health damage & -100 & 50 \\
23 & Damage due to international economic boycotts & -100 & 0 \\
24 & Damage due to international legal counter measures & -100 & 0 \\
25 & Environmental damage & -40 & 100 \\
\hline
\end{tabular}

scores, where the score of the policy option reflecting the current situation was set to zero. Scoring was conducted over three days, in two parallel groups of experts. To attain a good balance between the ratings, policy instrument options was scored groupwise i.e. per cluster in one session, and the rating of all sets of policy instrument options was successively completed per cluster. After the exchange of arguments and new information, consensus about the ratings was usually attained. If not, the average of the individual scores was set as the final score. Following each rating session, group members were asked to rate, on a scale from 0 to 100 , their confidence in the set of scores just given. Finally, experts were given the opportunity in plenary sessions to challenge and adjust the obtained scores at the end of the day.

Step 5 and 6 . Weighting factors and final scores

According to MC-MCDA, every outcome criterion within the outcome cluster and the six outcome clusters must be weighed against each other to account for their relative impact on the overall (final) score of the policy models per se, as well as, to adjust for clusters with relatively many outcomes (i.e. a cluster containing six outcomes adds up 3-fold more scores than a clusters containing two outcomes). First, every expert selected the most important outcome in each cluster and set its weight on 100. Next, every expert assigned per cluster a weight value to the remaining criteria in that cluster, relative to the just designated most important outcome of that cluster ( $\mathrm{n}=25 \mathrm{~W} 2$ 's; on a scale of $0-100)$. Finally, the same procedure was applied for the six weight values (W1) of clusters A to F. The mean value of each experts' weight values (W1's and W2's) was calculated (cf. Table 3). The weighting factor of the cluster with the highest mean value was set at 100 and the residual five cluster weights (W1's) were 
Table 3. Weighing factors (W1) of the six outcome clusters in the upper panel and the 25 outcome criteria with their mean weighing factor (W2) and their overall weighing factor (W1 x W2) in the lower panel.

\begin{tabular}{|c|c|c|c|c|}
\hline \multicolumn{2}{|c|}{ Cluster } & Outcome cluster & W1 (as rated) & W1 (\%) \\
\hline \multicolumn{2}{|c|}{$A$} & Use (prevalence \& patterns) & 69 & 18 \\
\hline \multicolumn{2}{|c|}{ B } & User health & 100 & 26 \\
\hline \multicolumn{2}{|c|}{$\mathrm{C}$} & Crime & 89 & 24 \\
\hline \multicolumn{2}{|c|}{$\mathrm{D}$} & Financial costs and benefits & 36 & 10 \\
\hline \multicolumn{2}{|c|}{$\mathrm{E}$} & International politics & 25 & 7 \\
\hline \multicolumn{2}{|c|}{$\mathrm{F}$} & Environmental protection & 58 & 15 \\
\hline \multicolumn{4}{|c|}{ SUM A-F } & 100 \\
\hline \multicolumn{2}{|c|}{ Nr. $\quad$ Cluster } & Outcome criterium (cluster item) & W2 ${ }^{\#}$ & Overall weight ${ }^{*}$ \\
\hline \multirow{3}{*}{$\begin{array}{l}1 \\
2 \\
3\end{array}$} & $A$ & Use frequency and intensity by users & 100 & 5.3 \\
\hline & A & Use in vulnerable populations & 96 & 5.1 \\
\hline & A & Prevalence (general population) & 74 & 3.9 \\
\hline$\frac{3}{4}$ & $B$ & Quality of information about MDMA & 91 & 7.0 \\
\hline 5 & B & Health damage & 100 & 7.6 \\
\hline 6 & B & Stigmatization of users & 72 & 5.5 \\
\hline 7 & B & Social benefits & 47 & 3.6 \\
\hline \multirow{2}{*}{$\begin{array}{l}8 \\
9\end{array}$} & B & Health benefits & 45 & 3.5 \\
\hline & B & Social damage & 69 & 5.3 \\
\hline 10 & B & Shift to other drugs & 69 & 5.3 \\
\hline \multirow{2}{*}{$\begin{array}{l}11 \\
12\end{array}$} & C & Organized crime (MDMA-related) & 100 & 6.8 \\
\hline & C & Criminalisation of users & 76 & 5.2 \\
\hline 13 & C & MDMA-related small crime & 32 & 2.2 \\
\hline \multirow{2}{*}{$\begin{array}{l}14 \\
15\end{array}$} & C & Organized crime (not MDMA-related) & 81 & 5.6 \\
\hline & C & Criminals exploitating vulnerable groups & 80 & 5.5 \\
\hline 16 & $\mathrm{C}$ & International trafficking of MDMA & 65 & 4.4 \\
\hline \multirow{2}{*}{$\begin{array}{l}17 \\
18\end{array}$} & $\mathrm{D}$ & State revenue (other) & 41 & 1.1 \\
\hline & D & State revenue (VAT) & 47 & 1.3 \\
\hline 19 & D & Costs related to pollution (dumpings) & 73 & 2.0 \\
\hline \multirow{2}{*}{$\begin{array}{l}20 \\
21\end{array}$} & D & Costs related to health damage & 100 & 2.8 \\
\hline & $\mathrm{D}$ & Costs related to crime & 87 & 2.4 \\
\hline \multirow{3}{*}{$\begin{array}{l}22 \\
23 \\
24\end{array}$} & $\mathrm{E}$ & Damage to the Dutch Image & 51 & 1.0 \\
\hline & $\mathrm{E}$ & Damage due to international economic boycotts & 77 & 1.5 \\
\hline & $E$ & $\begin{array}{l}\text { Damage due to international legal counter } \\
\text { measures }\end{array}$ & 100 & 1.9 \\
\hline 25 & $\mathrm{~F}$ & Environmental damage & 100 & 4.4 \\
\hline \multicolumn{4}{|c|}{ SUM $1-25$} & 100 \\
\hline
\end{tabular}

\# as rated, but rescaled between 0-100; * Overall weight factor based on W2 $\times$ rescaled W1 (for details see Methods); ${ }^{* *}$ in the EU, illegal goods, including illegal drugs, are not subject to VAT. 
rescaled accordingly (related to 100). The mean W2-values were multiplied by the rescaled W1 of the corresponding cluster. Using the sum of the $25 \mathrm{~W} 2$-values, the overall weight factor of each outcome criterion (W1xW2) was rescaled to proportions (sum of the 25 overall weight factors $=100$ ). The final scores per policy option were obtained by multiplying the option score by the corresponding overall weight factor (cf. Table 1). Summation of the $550(22 \times 25)$ weighted final option scores gives the overall score (final score) of the model.

\section{Results}

According to MDMA's scheduling on List I of the Dutch Opium law, the production, import, export, possession, advertising, trade, and sales to consumers related to MDMA are currently prohibited in the Netherlands. Consumption of MDMA is not prohibited. The following issues related to MDMA have not been described in Dutch legislation: packaging requirements, age limit for users, price, quality requirements and management, licenses for sale.

The experts collectively rated the effect of the 95 policy instrument options on the 22 outcomes ( $n=2,375$ scores) and individually attributed a weight value for each of the 25 outcomes and the six outcome clusters. The mean values of the overall weighting factors are depicted in Table 3. Based on these final scores per policy option, the overall scores of the different policy models were obtained by summation of the appropriate 25 final scores (see below for results).

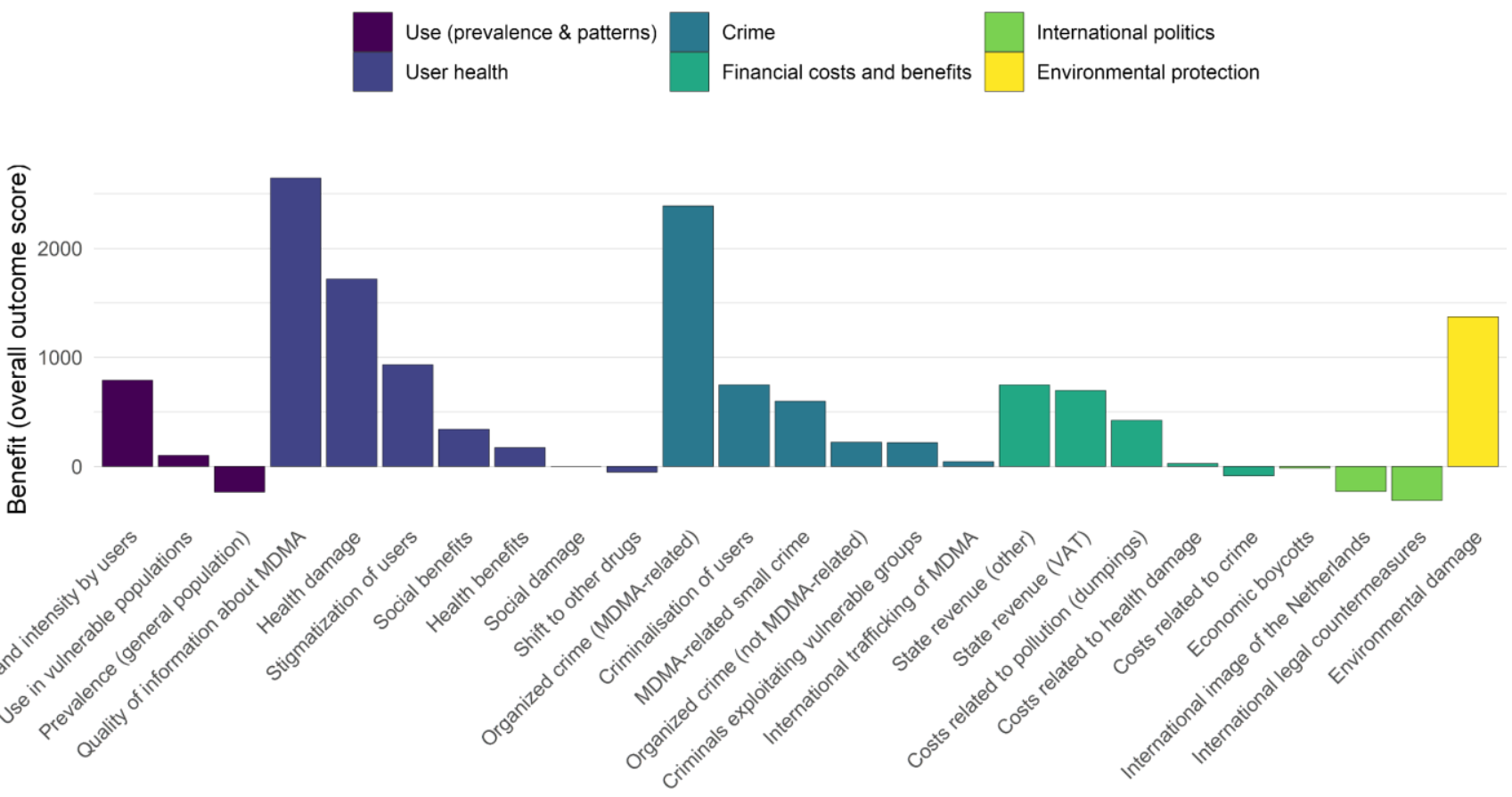

Figure 2. The optimal policy consisting of the best-scoring policy instrument options. 
Obviously, the worst and the optimal model reflect the bounds where all possible models will always fall between i.e., the window. The higher the overall score, the better the model. The optimal (best possible) policy model scored 13,270 points higher/better than the current situation, which was set at zero (cf. Table 4 and 5). The worst possible model scored 7,252 points lower/worse than the current situation (cf. Table 5). Figure 2 shows the benefits of the optimal model per outcome as compared with the current situation. In particular, the main benefits of the optimal model are gains in health and social benefits, better prevention of MDMA-related organised crime, as well as, increased state revenues. These benefits are accomplished by selecting policy instrument options from those described in table 4 (see Table S2 for the 22 selected options), including legal requirements for selling ecstasy, monitoring, and quality requirements for ecstasy. In the worst possible model, certain policy instrument

Table 4. The 22 policy instrument options that collectively lead to the optimal model i.e. options giving the highest overall score for the 25 outcomes, and the improvement/deterioration compared to the current situation.

\begin{tabular}{|llc|}
\hline Instrument & Best instrument option & Score* \\
\hline Legal requirements for selling & Only license holders may sell & 1,611 \\
Monitoring & Extensive & 1,538 \\
Quality rules & Quality requirements are laid down by law & 1,412 \\
Production & Similar to pharmaceutical legislation & 1,161 \\
Health education & The government largely subsidizes & 1,027 \\
Confiscation & More expertise and effort needed & 914 \\
Sanctioning QA rules & Violation is punished severely & 907 \\
Sales to users & Regulated & 896 \\
Sales between companies & Similar to pharmaceutical legislation & 881 \\
Punishable & Seller is punishable if not adhering to the age limit & 729 \\
Health information & Harm reduction & 609 \\
Packaging & 'Plain packaging' + prevention message & 520 \\
Pricing policy for sale to users & A legally determined minimum price & 435 \\
Age limit & No age limits & 290 \\
Advertising & All advertising is allowed & 203 \\
Priority crime fighting & Selective (high priority for serious MDMA-related & 88 \\
Export & crime, but low priority for that of consumers) & 48 \\
Maximum penalty & Export is legalized & 27 \\
International treaties & Increase current maximum penalty & 5 \\
Control prevention policy & Inter se & 0 \\
Which government & Predominantly by prevention organizations & National and regional government \\
Possession & Tolerate user quantity & -29 \\
\hline SUM & & 13,270 \\
\hline
\end{tabular}

* A positive/negative number indicates an improvement/deterioration compared to the current situation; " responsible for prevention policy. 
Table 5. The final overall score of six policy models, the optimal and worst possible model compared to the current situation (set as zero). Worst score (minimum score) was - 7,252.

\begin{tabular}{|l|c|}
\hline Policy model & Overall score \\
\hline Optimal (maximum score) & $+13,270$ \\
\hline X-shop & $+12,699$ \\
\hline Adapted coffeeshop & $+10,721$ \\
\hline Coffeeshop & $+5,528$ \\
\hline Free market & $-2,244$ \\
\hline Repressive & $-2,778$ \\
\hline
\end{tabular}

options had a strong negative impact on the overall score, whereas other options had little or no effect or even a small positive effect on the overall score (heatmaps are available in the OSF repository for this project). In particular, repressive policy options like 'possession prohibited', 'high priority for fighting serious crime', 'no subsidy for health education', 'abstinence as prevention perspective' and 'no monitoring' strongly decreased the overall score, indicating that - based on the available scientific evidence - experts rated those options as having a (very) negative impact on important outcomes.

In order to position the optimal model, the characteristics of the optimal model and two legal

\section{Optimal model}

- Sales of MDMA to users is legally regulated, whereas that between companies complies to pharmaceutical legislation. Only license holders may sell MDMA to users. There are no user age limits, but MDMA must be sold at a fixed minimum price, 'plain' packaged with a prevention message, and meet quality requirements as imposed by law; violation of QA rules is severely punished. Possession of a user quantity of MDMA is tolerated and all advertising is allowed.

- MDMA-production is legalized, but is subjected to licensing and production rules similar to pharmaceutical legislation.

- Fighting serious MDMA-related crime is prioritized (but low for consumers), whereby the current maximum penalty is increased and more expertise and effort is generated to confiscate illegitimately obtained properties. Export of MDMA is legalized and an 'Inter se' position for the new model within international drug treaties will be applied for.

- The national/regional government is responsible for the prevention policy and subsidizes health education. Predominantly prevention organizations supply of information about health effects and is focused on harm reduction. Adverse effects of MDMA use will be extensively monitored.

\section{X-shop model}

Specifications deviating from the optimal model: (1) user quantity is legal and larger quantities condoned, (2) all advertising is prohibited, (3) sales of MDMA to users is subjected to pharmaceutical legislation, (4) age limit is 18 years, (5) export is illegal, and (6) all governmental bodies are responsible for prevention policy. 
drug models in the Netherlands (the coffeeshop model and the adapted coffeeshop model) were compared in terms of policy instrument options and overall scores. The characteristics of the three policy models with their applicable instrument options are depicted in table S1. Table 5 depicts the overall score of the optimal model and the two legal policy models and shows that the optimal model scores better than the adapted coffeeshop model and the coffeeshop model.

The characteristics of the optimal and the X-shop model are described in the text box above. To accommodate both political feasibility and social acceptance of regulated ecstasy sales, the optimal model was slightly adjusted at six minor points to construct a new, nearly optimal and a politically more feasible model: the X-shop model. Of the six adjustments (see Table S2), the change in (1) the possession option from 'tolerate user quantity' to 'user quantity is legal and a large quantity is tolerated' and (2) the advertising option from 'allowed' to 'prohibited' had the strongest negative impact on the overall score compared to the optimal model (decreases in overall score by 148 and 203 points, respectively). The other four adjustments, such as (3) the sales to users option from 'regulated' to a 'pharmaceutical legislation regime', and (4) the government responsible for prevention policy option from 'national/regional' to 'all governmental bodies', had much smaller effects on the overall score of the optimal model. See table S2 for a detailed description of the policy options of the X-shop model. Figure 3 summarises the differences in outcomes between the X-shop model, optimal model and the

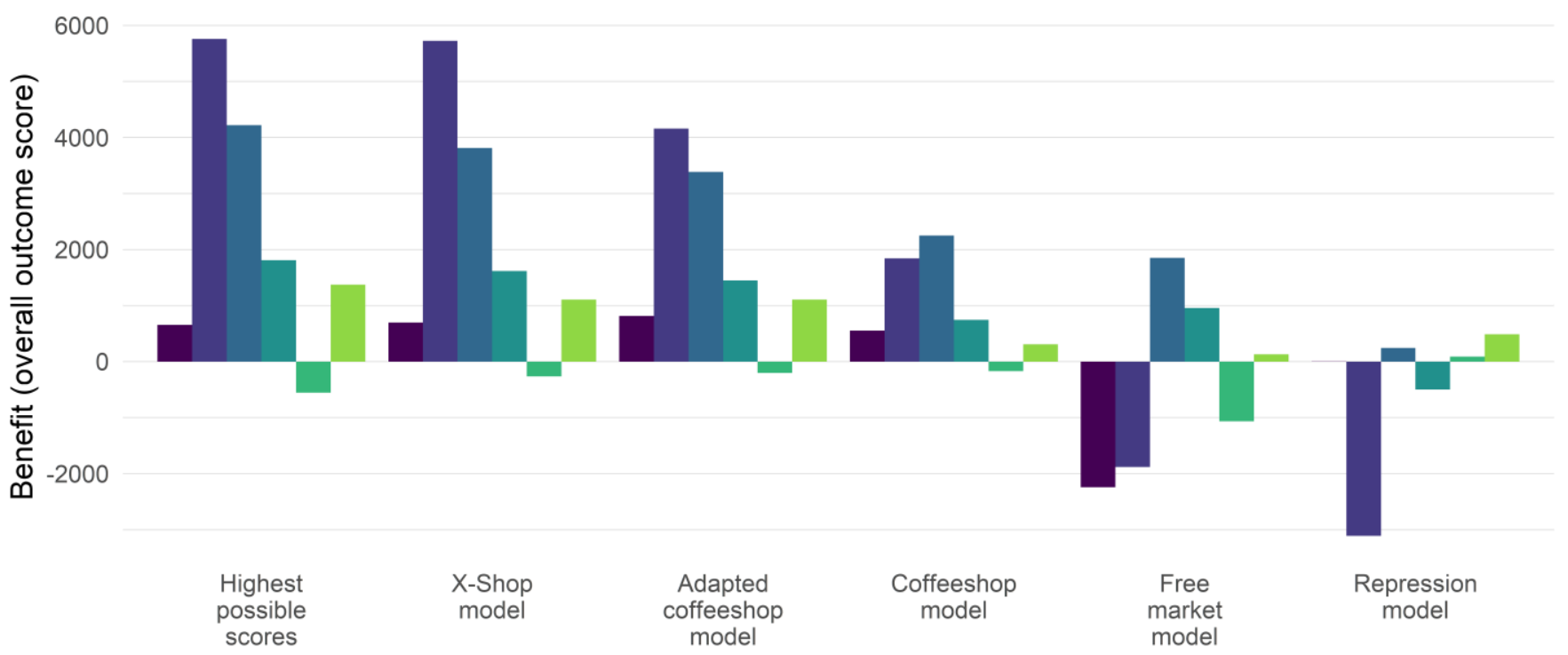

Figure 3. A comparison of every model's score in each criterion cluster. 
other four policy models at cluster level. It shows that the optimal model is superior at all cluster levels, except, in some cases, for international status. Furthermore, despite the six minor changes introduced, the scores at cluster level of the optimal model and X-shop model are virtually the same which is agreement with minor difference in overall score (cf. Table 5).

\section{Sensitivity analyses}

Two types of sensitivity analyses were conducted to assess the robustness of the findings to changes in the scores and the weights that were employed. To explore the first, all the scores with a confidence rating lower than a given threshold were replaced by either (1) the highest possible score for each policy option; (2) zero; and (3) the lowest possible score for each policy option. Next, we repeated this procedure stepwise with steps of 0.1 points for all confidence thresholds between $0-1$. This procedure revealed two clusters: a "high" scoring (better outcome) cluster containing the optimal, the X-shop, coffeeshop and the adapted coffeeshop model, and a "low" scoring (worse outcome) cluster containing the free market and the repression model. The models sometimes changed rank order within their cluster when many estimates were replaced by the highest and lowest possible estimates, but the models in the high cluster never scored equal or lower than models in the low cluster (and vice versa). Robustness against changes in weight factors was assessed by computing each model's scores using the weight values given by the experts individually instead of the average weights. As a result, the same stable clustering of the six models as described above was obtained, i.e. the same stable clustering of the six models described above in a "high" scoring and a "low" scoring cluster was obtained when the weightings factors of each expert were applied. Inspection of the individual weighting factors shows that the experts ranked all six models in (virtually) the same way (cf. Figs. S1 and S2 in Supplementary material).

\section{Discussion}

The current multi-decision multi-criterion decision analysis (MD-MCDA) based on experts ratings of 95 policy options on 25 policy outcomes has led to the development and description of an optimal model with the overall best outcome as basis for a new and science-based MDMA policy in the Netherlands. The optimal model proposes regulated MDMA sales and predicts decrements in health harms, MDMA-related organised crime, and environmental 
damage as well as increments in state revenues, quality of MDMA products and user information. The optional model was then slightly modified into the X-shop model; a model that is considered to be politically more feasible and will presumably lead to health and social benefits, although with a minor increase in the prevalence of use. Presumably, user health is most improved by legal obligations to formulate legal requirements for selling ecstasy, to monitor and to control the quality of ecstasy pills (cf. Table 4). Another important element of the optimal model is the firm decrease in the level of MDMA-related organized crime (cf. Fig. 2). The latter is crucial to obtain societal and political support from the so-called 'Law and Order' political parties who highly value reductions in crime, in particular crime intertwined with Dutch ecstasy production and consumption. Furthermore, the proposed X-shop model provides - based on the ratings given in the assessment - a better protection of vulnerable users, though incrimination of users will slightly increase due to stricter regulation under the optimal regime. According to the proposed X-shop model, the prevalence of ecstasy use will slightly increase, because of the higher availability and the implicit governmental legitimation of ecstasy use. On the other hand, better pill quality rules and improved health education will in our view counterbalance the slight increase in ecstasy use and lead to a safer use of ecstasy with an overall reduction in adverse health effects. Moreover, the seven outcome criteria in the cluster 'User health' collectively indicate a profound improvement in user's benefits-risks as compared with the current situation (cf. Fig 3). Despite a slight increase in prevalence of use, an increase in the level of ecstasy dependence is not expected mainly because of the low dependence potential of ecstasy (Alderliefste and Damen 2018; EMCDDA 2019; van Laar et al. 2019). A specific advantage of regulated ecstasy sales in the X-shop model is the modest generation of state revenues consisting of VAT, income tax, fees of license holders and excise duties. More relevant however, are the financial benefits resulting from a reduction in costs of health care, environmental pollution, and crime, including lower expenses for drug enforcement (see below).

The optimal model includes the 'inter se' option for treaty modification, as provided by Article 41 of the 1969 Vienna Convention on the Law of Treaties. Inter se modification is a procedure specifically designed to find a balance between treaty regime stability and the need for change in absence of consensus, whereby a group of two or more like-minded states could reach agreements among themselves that permit the production, trade, and consumption of 
scheduled substances for non-medical and non-scientific purposes, while minimizing the impact on other states and on the goals of the drug conventions (Boister and Jelsma 2018). Following international consultations and negotiations through the inter se option, neighbouring countries may implement comparable legislation. Legal producers in the Netherlands can then supply high quality MDMA-products to consumers in those countries (and vice versa). The more countries adapting such legislation, the more effectively MDMArelated organized crime is side-lined. One of the elements of the optimal model proposed is a more efficient confiscation of goods and finances obtained by the illegal production of and trade in MDMA, including better coordination with foreign partners. An even more important element of this regime is prioritization of fighting crime intertwined with the production of and trade in MDMA. However, it is beyond the scope of this investigation to outline initiatives in the frame of more efficient and smarter investigation methods in drug enforcement. Moreover, a number of innovative targets have already been mentioned by the Minister of Finance and the Minister of Justice and Security in their letter to the Dutch Parliament describing initial contours of the broad-based offensive against organised, subversive crime (Dutch Government 2019a, 2019b, 2019d).

\section{Strengths and Limitations}

The main strength of the current study is that the expert panel consisted of experts from a broad range of expertise domains. Their specific expertise was extended by supplying them with an extensive state-of-the-art literature review about ecstasy, covering all outcome criteria (van Amsterdam et al. 2020a; van Amsterdam et al. 2020b). Moreover, rating of the policy options was performed in an efficient manner using a structured decision-making model with a broad range of policy instruments and outcomes as the building blocks for a revised national ecstasy policy model. Compared to some other consensus models, the current approach is fully transparent. The judgements and weights currently used by the expert panel can be varied, so that the effects of theses variations on the outcome (best model) can be easily tested (a publicly available website fully disclosing the data facilitates such testing). Moreover, the sensitivity analyses performed indicated high robustness of the outcomes. For instance, the outcomes of the current MD-MCDA exercise were robust against (extreme) changes in judgements and weights._The main limitation of this project is the selection of the experts and their individual 
assessments, both of which may suffer from subjectivism that arises from personal, ethical, and/or political views. However, the impact of this potential bias has been mitigated by (1) deliberately including experts from law enforcement agencies and experts with a relatively conservative attitude towards the liberalization of drug laws, and (2) regularly challenging the experts during the rating sessions to give science-based arguments for their rating. Furthermore, the selection of policy instruments and outcomes was not idiosyncratic but based on previous studies on similar issues (Nutt et al. 2007; Nutt et al. 2010; Rogeberg et al. 2018; van Amsterdam et al. 2015a; van Amsterdam et al. 2015b). Finally, sensitivity analyses showed that the outcomes of the current MD-MCDA are robust and independent of both the uncertainty of the ratings and any extreme position(s) taken by individual experts. Therefore, we believe that the proposed models represent the currently most adequate evidence-based estimation of benefits and risks of different national ecstasy policies, including both the Netherlands and other countries.

\section{Conclusion}

Using multi-decision multi-criterion decision analysis (MD-MCDA), the optimal MDMA policy model, as well as its slightly fine-tuned variant i.e., the X-shop model, can serve as a new initiative to adjust the legal basis of the Dutch MDMA-policy, because it predicts a major health benefit and takes into account the current criminal burden. Given the robustness of these models, it is likely that this will also be true for the MDMA-policy in other countries.

\section{Acknowledgment}

These results have been obtained thanks to the experts who have carried out their work with great dedication, expertise, and enthusiasm. Without them this result would not have been achieved. Finally, we are thankful to Sarah Graman and Tom Bart for their secretarial support, Dirk Korf and Raimond Dufour for moderating the sessions, and Larry Phillips for his expert advice on designing the MD-MCDA model.

\section{Declaration of conflicting interests}

The authors declared no potential conflicts of interest with respect to the research, authorship, and/or publication of this article. 


\section{Funding}

The authors received no financial support for the research, authorship and/or publication of this article.

\section{Full disclosure}

All materials, scripts, data, and output generated in this project are available on the Open Science Framework repository for this project at: https://osf.io/pw4gh

\section{References}

Alderliefste GJ, and Damen J (2018). Partydrugsgerelateerde klachten. DOI:10.1007/s12445018-0285-y. Huisarts Wetenschap 61: 1-4.

Boister N, and Jelsma M (2018). Inter se modification of the UN drug control conventions: An exploration of its applicability to legitimise the legal regulation of cannabis markets. Int Commun Law Rev 20: 457-494.

Commission Knottnerus (2018). Advisory Committee Experiment Closed Cannabis Chain, chaired by A Knottnerus. An experiment with a closed cannabis chain. Available at: https://tinyurl.com/tx7mo2q (accessed 24 June 2020).

Dutch Government (2019a). F. Grappenhuis, Ministry of Justice and Security. Outlines of the Offensive against organised, subversive crime. Available at: https://tinyurl.com/rx5djrj (accessed 25 January 2020).

Dutch government (2019b). Minister Hoekstra and Grapperhaus. Plan van aanpak 'Witwassen'. [Plan of Action 'Money laundering']. Available at: https://www.rijksoverheid.nl/binaries/rijksoverheid/documenten/kamerstukken/2019 /06/30/aanbiedingsbrief-plan-van-aanpakwitwassen/Aanbiedingsbrief+plan+van+aanpak+Witwassen.pdf (accessed 25 January 2020).

Dutch Government (2019c). Ministry of Justice and Security and Ministry of Health, Welfare and Sport. Rules for the experiment with a controlled supply of cannabis to coffee shops. Available at: https://preview.tinyurl.com/rlv9ex8 (accessed 24 January 2020). 
Dutch Government (2019d). Ministry of Justice and Security. The initial contours of the broadbased offensive against organised, subversive crime. Available at: https://www.government.nl/topics/crime-and-crime-

prevention/documents/publications/2019/10/18/outlines-of-the-offensive-againstorganised-subversive-crime (accessed 25 January 2020).

EMCDDA (2019). European Monitoring Center for Drugs and Drug Addiction (EMCDDA). United Kingdom: Country drug report 2019. Lisbon, Portugal. Available at: http://www.emcdda.europa.eu/countries/drug-reports/2019/united-kingdom/keystatistics_en (accessed 23 January 2020).

Hall W, and Lynskey M (2009). The challenges in developing a rational cannabis policy. Curr Opin Psychiatry 22: 258-262.

Nabben T. (2010). High Amsterdam. Ritme, roes en regels in het uitgaansleven (thesis). Amsterdam: Rozenberg Publishers. Available at: https://pure.uva.nl/ws/files/17757542/Proefschrift.pdf (accessed 10 June 2020).

Nabben T, Luijk SJ, and Korf DJ. (2018). Antenne 2017. Trends in alcohol, tabak en drugs bij jonge Amsterdammers. Amsterdam: Rozenberg Publishers. Available at: http://www.bonger.nl/PDF/Antenne\%20Amsterdam\%202017.pdf (accessed 11 June 2020).

Nutt D, King LA, Saulsbury W, et al. (2007). Development of a rational scale to assess the harm of drugs of potential misuse. Lancet 369: 1047-1053.

Nutt DJ, King LA, and Phillips LD (2010). Drug harms in the UK: a multicriteria decision analysis. Lancet 376: 1558-1565.

Rogeberg O, Bergsvik D, Phillips LD, et al. (2018). A new approach to formulating and appraising drug policy: A multi-criterion decision analysis applied to alcohol and cannabis regulation. Int J Drug Policy 56: 144-152.

Szigeti B, Winstock AR, Erritzoe D, et al. (2018). Are ecstasy induced serotonergic alterations overestimated for the majority of users? J. Psychopharmacol. 32: 741-748.

Tops P, and Tromp J. (2019). De achterkant van Amsterdam. Een verkenning van drugsgerelateerde criminaliteit. Available at: https://assets.amsterdam.nl/publish/pages/918763/onderzoeksrapport_de_achterkant _van_amsterdam.pdf (accessed 5 January 2020). 
Tops P, van Valkenhoef J, van der Torre E, et al. (2018). Waar een klein land groot in kan zijn. Nederland en synthetische drugs in de afgelopen 50 jaar. Boom criminologie, Den Haag, The Netherlands. Available at: https:/tinyurl.com/yzk7pumj (accessed 24 January 2020).

van Amsterdam J, Nutt D, Phillips L, et al. (2015a). European rating of drug harms. J. Psychopharmacol. 29: 655-660.

van Amsterdam J, Opperhuizen A, Koeter M, et al. (2010). Ranking the harm of alcohol, tobacco and illicit drugs for the individual and the population. Eur. Addict. Res. 16: 202207.

van Amsterdam J, Phillips L, Henderson G, et al. (2015b). Ranking the harm of non-medically used prescription opioids in the UK. Regul Toxicol Pharmacol 73: 999-1004.

van Amsterdam J, Ramaekers JG, Nabben T, et al. (2020a). Use characteristics and harm potential of ecstasy in the Netherlands. Drugs: Education, Prevention \& Policy.

van Amsterdam JGC, Pennings E, and van den Brink W (2020b). Fatal and non-fatal health incidents related to recreational ecstasy use. J. Psychopharmacol. 34: 591-599.

van Laar MW, van Gestel B, Cruts AAN, et al. (2019). Nationale Drug Monitor. Jaarbericht 2018. Trimbos Instituut, Utrecht, The Netherlands. Available at: https://www.trimbos.nl/aanbod/webwinkel/product/af1643-jaarbericht-nationaledrug-monitor-2018 (accessed 24 January 2020).

van Laar MW, and van Ooyen-Houben MMJ. (2017). Nationale Drugs Monitor Jaarbericht 2016. Utrecht: Trimbos Instituut. Available at: https://www.trimbos.nl/docs/3fdeab39f34e-4aa0-97af-5dbf111c05a0.pdf (accessed 24 January 2020).

WHO (1985). World Health Organisation (WHO). WHO Expert Committee on Drug Dependence. 22nd Report. Technical Report Series 729. World Health Organization, Geneva 1985, ISBN $92 \quad 4 \quad 120729$ 9. Available at: https://apps.who.int/iris/handle/10665/39635 (accessed 29 January 2020).

WHO (2003). World Health Organisation (WHO). Chapter 2: Scheduling Criteria. WHO Technical Report Series, No. 915 - Thirty-third Report. Expert Committee on Drug Dependence. Available at: https://apps.who.int/medicinedocs/en/d/Js4896e/2.html (accessed 29 January 2020). 


\section{Supplementary material}

The supplementary material for this manuscript is available at the Open Science

Framework at https://osf.io/h58r6, and the contents of that repository have been frozen in a public registration in that project that is available at https://osf.io/pw4gh.

The most up-to-date version of these files is available at

https://gitlab.com/denktank/mdma-policy-mdmcda, and the rendered version of the $\mathrm{R}$ Markdown script that produces the results is hosted at GitLab pages at https://denktank.gitlab.io/mdma-policy-mdmcda.

The supplementary materials also include an app that allows specifying alternative scenarios (policy models) and weighting for the criteria (outcomes). This app is available through https://mdmapolicy.com/app.

Tables S1 and S2 and Figures S1 and S2 are referred to directly in the manuscript, and so have been included here. 
Table S1. Similarities and differences in the characteristics and overall scores of the Coffeeshop, the Adapted Coffeeshop, and optimal policy model. The symbol $X$ in bold and on a grey field denotes that the instrument option of the optimal model is deviant from either the Coffee shop model, the Adapted Coffeeshop model or both.

\begin{tabular}{|c|c|c|c|}
\hline Description of instrument options & $\begin{array}{l}\text { Coffee } \\
\text { shop }\end{array}$ & $\begin{array}{c}\text { Adapted } \\
\text { Coffeeshop }\end{array}$ & $\begin{array}{l}\text { Optimal } \\
\text { model }\end{array}$ \\
\hline Possession: tolerate user quantity & $\mathrm{x}$ & $\mathrm{x}$ & $\mathrm{x}$ \\
\hline Packaging: 'Plain packaging' plus prevention message & $x$ & $x$ & $\mathrm{x}$ \\
\hline All advertising is prohibited & $\mathrm{X}$ & $\mathrm{X}$ & \\
\hline All advertising is allowed & & & $\mathrm{x}$ \\
\hline Sales across companies: prohibited & $\mathrm{x}$ & & \\
\hline Sales across companies: regulated & & $x$ & \\
\hline Sales across companies: similar to pharmaceutical legislation & & & $\mathrm{X}$ \\
\hline Sales to users: regulated & $\mathrm{X}$ & & $x$ \\
\hline Sales to users: similar to pharmaceutical legislation & & $\mathrm{x}$ & \\
\hline No age limit for using and buying ecstasy & & & $\mathrm{x}$ \\
\hline The age limit for using and buying ecstasy is $18 \mathrm{yrs}$. & $X$ & $X$ & \\
\hline Punishable by not adhering to the age limit: nobody & $\mathrm{X}$ & $\mathrm{X}$ & \\
\hline Punishable by not adhering to the age limit: the seller & & & $x$ \\
\hline Legal requirements for selling: only license holders may sell & $\mathrm{X}$ & $\mathrm{x}$ & $x$ \\
\hline Pricing policy: none & $\mathrm{x}$ & & \\
\hline Pricing policy: a legally determined minimum price for sale to users & & $x$ & $x$ \\
\hline Quality: no requirements are laid down by law & $\mathrm{x}$ & & \\
\hline Quality: requirements are laid down by law & & $X$ & $X$ \\
\hline Sanctioning QA rules: not applicable & $\mathrm{X}$ & & \\
\hline Sanctioning QA rules: violation is punished lightly & & $x$ & \\
\hline Sanctioning QA rules: violation is punished severely & & & $\mathrm{X}$ \\
\hline Monitoring: extensive & $X$ & $X$ & $X$ \\
\hline Health education: the government largely subsidizes & $\mathrm{X}$ & $\mathrm{X}$ & $\mathrm{X}$ \\
\hline Control prevention: the government formulates goals and priorities & $\mathrm{X}$ & & \\
\hline Control prevention: predominantly by prevention organizations & & $\mathrm{X}$ & $\mathrm{X}$ \\
\hline Harm reduction as prevention perspective & $\mathrm{x}$ & $\mathrm{x}$ & $\mathrm{x}$ \\
\hline Type of government responsible for prevention policy: all & $\mathrm{X}$ & $\mathrm{x}$ & $\mathrm{X}$ \\
\hline Production of ecstasy: prohibited & $x$ & & \\
\hline Production of ecstasy: similar to pharmaceutical legislation & & $x$ & $x$ \\
\hline Legal status of export of ecstasy: illegal & $\mathrm{X}$ & $\mathrm{X}$ & $\mathrm{X}$ \\
\hline International treaties: toleration & $\mathrm{X}$ & $\mathrm{x}$ & \\
\hline International treaties: inter se & & & $\mathrm{X}$ \\
\hline Priority crime fighting high (against serious MDMA-related crime) & $x$ & $\mathrm{x}$ & \\
\hline $\begin{array}{l}\text { Priority crime fighting selective (high priority for fighting serious } \\
\text { MDMA-related crime, but low priority for that of consumers) }\end{array}$ & & & $\mathrm{X}$ \\
\hline Maximum penalty: current maximum penalty is sufficiently high & $x$ & & \\
\hline Maximum penalty: increase the current maximum penalty & & $x$ & $x$ \\
\hline Confiscation: level of expertise and effort is sufficient & $\mathrm{X}$ & & \\
\hline Confiscation: more expertise and effort needed & & $\mathrm{X}$ & $X$ \\
\hline Overall score compared to the current situation & $+5,528$ & $+10,721$ & $+13,270$ \\
\hline
\end{tabular}


Table S2. The 22 policy instrument options of the X-shop model. The four adaptations of optimal model are reflected in italic.

\begin{tabular}{|c|c|c|}
\hline \multicolumn{2}{|c|}{ Policy instrument } & \multirow{2}{*}{$\begin{array}{l}\text { Policy instrument option } \\
\text { User quantity is legal and a large quantity is } \\
\text { condoned }\end{array}$} \\
\hline 1 & Possession of MDMA & \\
\hline 2 & Packaging of MDMA-products & 'Plain packaging' + prevention message \\
\hline 3 & Advertising MDMA-products & All advertising is prohibited \\
\hline 4 & Sales of MDMA-products between companies & Similar to pharmaceutical legislation \\
\hline 5 & Sales of MDMA-products to users & Similar to pharmaceutical legislation \\
\hline 6 & Age limit purchase and/or use of ecstasy & Age limit is 18 years \\
\hline 7 & Punishable when selling ecstasy & $\begin{array}{l}\text { Seller is punishable if the age limit is violated } \\
\text { (however, not applicable in this model) }\end{array}$ \\
\hline 8 & Legal requirements for selling & Only license holders may sell ecstasy \\
\hline 9 & Pricing policy for sale of ecstasy to users & A legally determined minimum price \\
\hline 10 & Quality rules MDMA-products & Quality requirements are laid down by law \\
\hline 11 & Sanctioning of quality rules & Violation is punished severely \\
\hline 12 & $\begin{array}{l}\text { Monitoring of product quality, prevalence and } \\
\text { incidents }\end{array}$ & Extensive \\
\hline 13 & Health education about the use of ecstasy & The government largely subsidizes \\
\hline 14 & Control over prevention policy & Predominantly by prevention organizations \\
\hline 15 & Health information about the use of ecstasy & Harm reduction \\
\hline 16 & Prevention policy & All governmental bodies are responsible \\
\hline 17 & Production of MDMA & Similar to pharmaceutical legislation \\
\hline 18 & Export & Export is illegal \\
\hline 19 & International treaties & Inter se \\
\hline 20 & Priority crime fighting & Selective * \\
\hline 21 & $\begin{array}{l}\text { Penalty for illegal production and trafficking of } \\
\text { MDMA }\end{array}$ & Increase current maximum penalty \\
\hline 22 & $\begin{array}{l}\text { Confiscation of money and goods (criminal } \\
\text { profits) }\end{array}$ & More expertise and effort needed \\
\hline
\end{tabular}

Option 1, 3, 5, 6, 16 and 18 of the optimal model were adapted. The original options in the optimal model were: (1) 'condone user quantity' as possession option, (2) 'allowed' as advertising option, (3) 'regulated' as the sales to users option (4) 'No age limits' as age limit to purchase, (5) 'national/regional' as the government responsible for prevention policy, and (6) 'Export is legalized' as export option. * high priority for serious MDMA-related crime, but low priority for that of consumers. 
Sensitivity analysis (scorer-weight-based) score plot

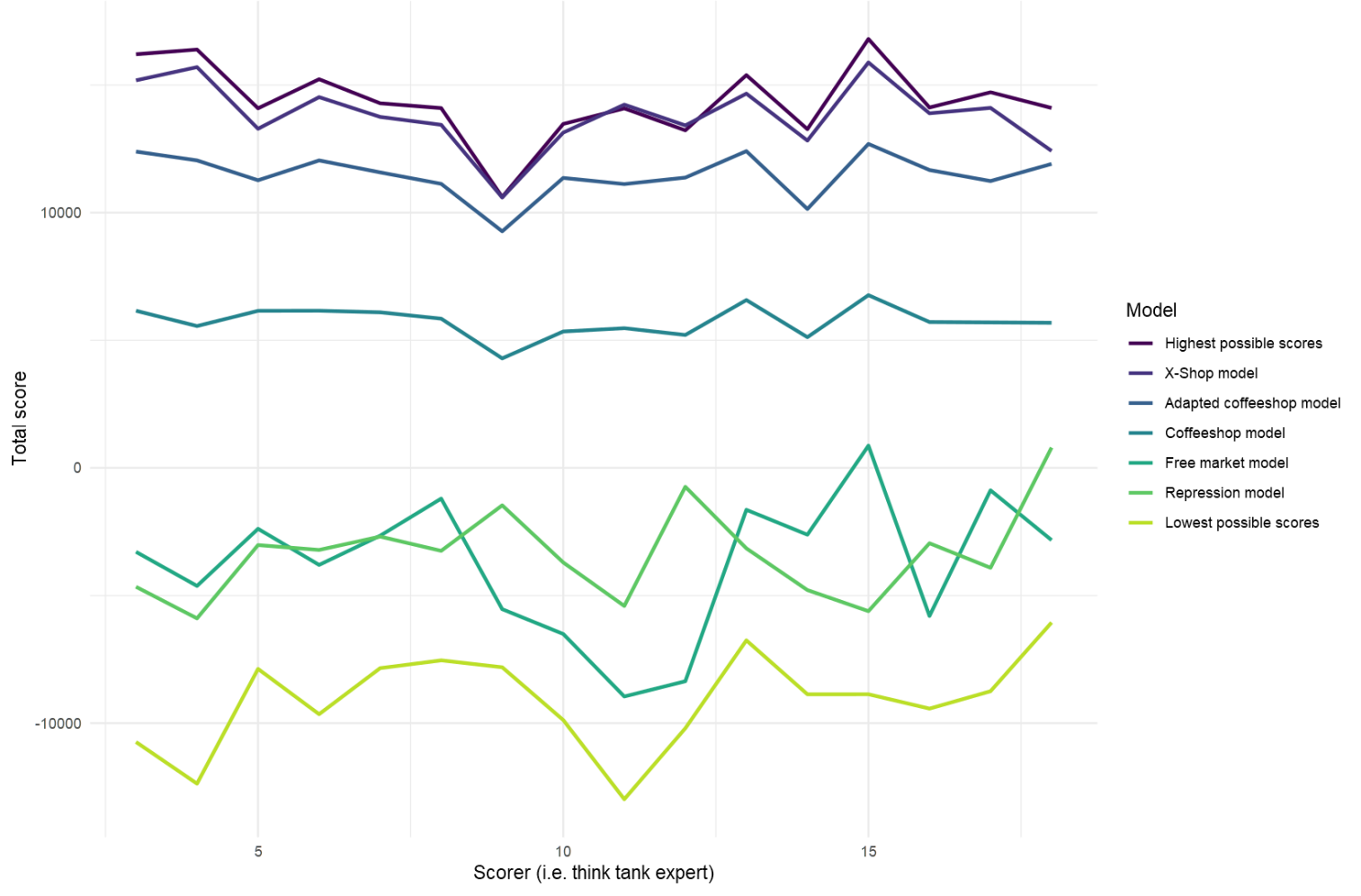

Figure S1. Rank order of the six models when the individual weighting factors of the experts are used to obtain the overall score of each model.

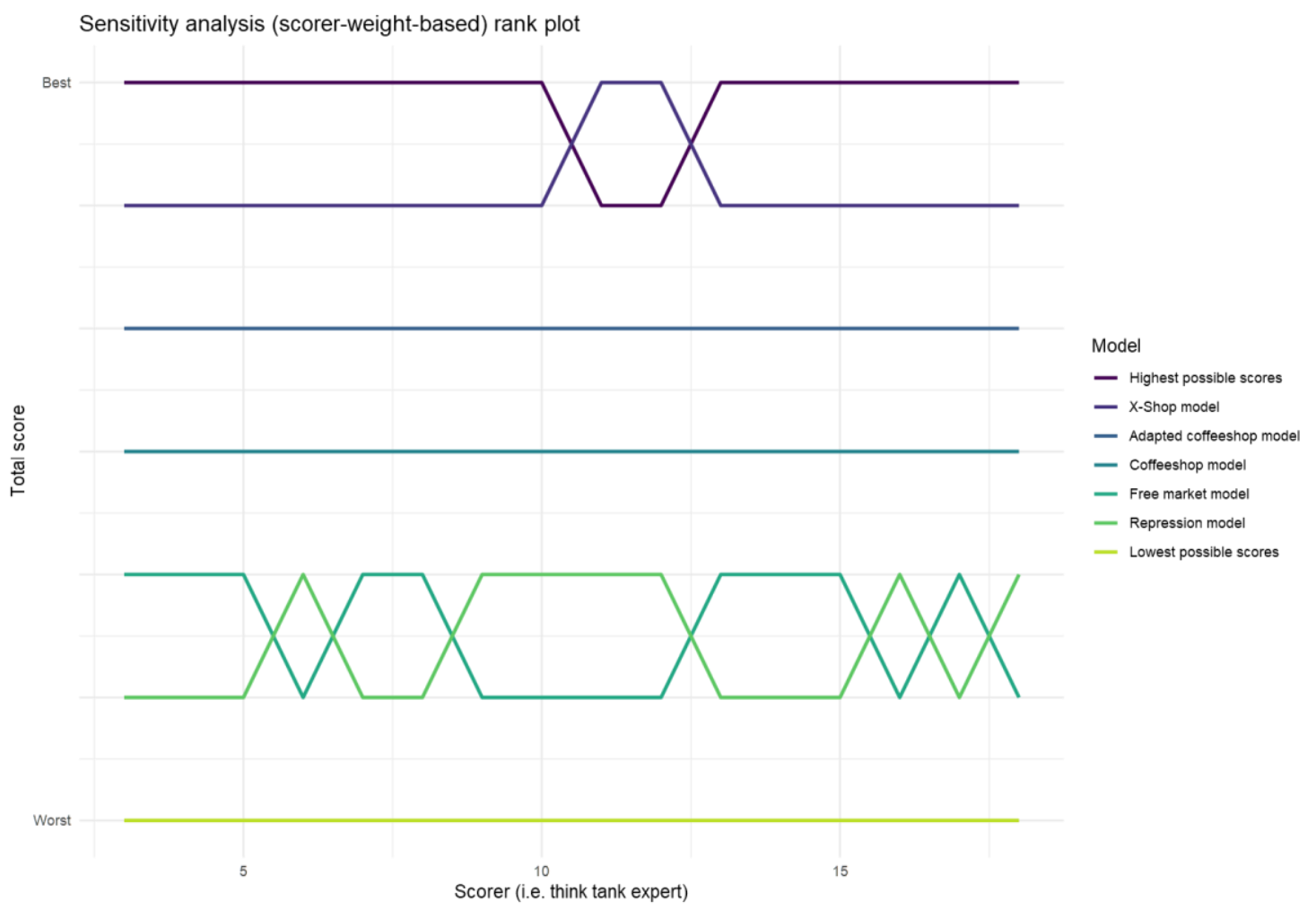

Figure S2. Overall scores of the six models using the individual weighting factors of the experts. 